\title{
Psycho-behavioral impact of yog practice among daily life of the youth population-a study report
}

\begin{abstract}
Bodies are destroyed by rule of nature but human aspirations are going present life to next life. Habit, behaviour and principal are basic pillars of personality of a person. Indeed, behaviour is the reflection of observation, learn and practice. In social science so many psycho-behaviour therapies are there to control imbalances of human behaviour. Here in this study it is observed that $y o g$ able to promote positive impact among 39 psycho-behavioral components i.e

Depression, Frustration, Grief, Insecurity, Jealousy, Mental irritation, Nervousness, Stress, Tension, Annoy, Quarrel intention, Malicious intention, Mental calmness, Altruism, Patience, Social accountability, Self-Confidence, Empathic outlook, Integrity, Non-judgmental attitude, Non-violence attitude, Punctuality, Dignity, Acceptance, Adjustment, Attention, Concentration, Impartiality, Decision making time, Emotional control, Eye-hand coordination, Recollection, Notice and situation analysis, Reacting/ responding time, Avoiding unwanted circumstance, Manner, Politeness, Solidarity, Cheerful view and functioned as a method of BCC (Behaviour Change Communication)
\end{abstract}

Keywords: behaviour change communication, psycho-behaviour, effect of yog
Volume I Issue I - 2017

\author{
Niladri Sekhar Ghosh,' Santwana Adhikari² \\ 'Ph. D Scholar Sai Nath University, India
}

${ }^{2}$ Research Supervisor, Sai Nath University, India

Correspondence: Niladri Sekhar Ghosh, Ph.D Scholar Sai Nath University, India, Email niladri.socialwork@gmail.com

Received: October 10, 2016 | Published: February 03, 2017

\section{Introduction}

Bodies are dies but traits cannot destroy by materialistic elements. Traits of a person are also going from past life to next life during energy cycle. In the time of death the space element of the body is moved from the cadaver and rest four elements of bodies-fire, water, earth and air are also isolated from the body and amalgamated with universal elements during the obsequies work. The human traits are passing with bodily five elements as a form of different code. According to Indian mythology $1 / 3 \mathrm{rd}$ trait of a person is also related to the past life and among rest $2 / 3$ rd traits $1 / 3$ rd is coming from heredity and $1 / 3 \mathrm{rd}$ is developed through interaction with society. In a single word trait of a person is constructed with habit, behaviour and principal of a person. Itself behaviour is the reflection of observation, learn and practice of a person. In social science, the word behaviour is defined as "Behavior is something that a person does that can be observed, measured, and repeated. When we clearly define behavior, we specifically describe actions (e.g. Sam talks during class instruction). We do not refer to personal motivation, internal processes, or feelings (e.g. Sam talks during class instruction to get attention)". ${ }^{1}$ Every moment of life people has been adopting different experience from the day to day life. Human minds are always capturing different observations and gradually observations are converted to experiences and experiences are developing a principal regarding lifestyle. Finally, the principles are reflected through practices in life. Practices of a person are renowned as habit and attitude in social science. Initially, habit and attitude are correlated and the seed of behaviour, attitude from a long time have been constructed the behaviour of a person. Mental images are reflecting through the behaviour. Behaviors are carrying the social identity and impression of person in society. It is the indicator to measure the level of cultural faculty and social skills. Although it is clear that psychological setup and behaviour both are correlated. Therefore, it is possible to do the change overlook and life pattern of a person throughout behaviour changes. In social science, the concept of BCC (Behaviour Change Communication) is known method to modification the behaviour of a person. Different kind of behavioral therapies had been used on above aspect based on the situation and condition of a patient. Itself behaviour is the mirror of mind and approaches are the pillar of behaviour. In this study it was seeking that psycho-behavioral effect of yog practices on day to day life of present generation youth KMA region and 39 common psycho-behavioral components were selected to see the result. Here in this study, the term psycho-behaviour was used to indicate few specific behaviors affected by amiable enforce of psychological setup and reflected from behaviour in daily life.

\section{Research methodology}

Research methodology is the spirit of successful research. In this study the research designing was interpreted as follows process:

\section{Geographical limitation}

The geographical limitation of this study was bounded in the urban region of KMA (Kolkata Metropolitan Area) area of West Bengal, India, according to the area map of Kolkata Metropolitan Authority.

\section{Age group of respondents}

Age group of respondent was 15 to 35 years, old people.

\section{Timeline}

The period of the research was April 2014 to April 2016.

\section{Data collection and analysis process}

The methodology of data collection, analysis and interpretation was processed as follows:

Data collection: The study was depended on primary and secondary both database and collection process had processed through below mention protocols: 
Primary data: Primary database was collected with two times from "target" and control" both groups. First round database was collected before stating yog and second round database was collected from same person after 6 months interval. Therefore, Score from $2^{\text {nd }}$ round$1^{\text {st }}$ round $=$ positive changes.

Sample size: Collected primary data from 1,000 respondents.

Sampling technique: This research was based on the comparison between the life before $y$ og practice and after $y$ og practice. Respondents were homogeneous. Therefore, primary data was collected through liner snowball sampling technique.

Process of data collection: Primary data collection in this study executed through two different processes as follows:

Interview: Personal interview was done with below mention process:

Type of interview: Questionnaire format was finalized based on the report of the pilot survey.

Questionnaire pattern: Open and closed both types of questions were enlisted in the questionnaire. For the reason to see the impact of $y o g$ on the daily life major portion of questions in the questionnaire was formed with particular indicators

Physical observation: Physical observation was addressing the gap of interview format. It helped to strengthen the research report.

Data tabulation, compilation and analysis: Data tabulation, compilation and analysis processes were processed through different tables.

\section{Data analysis and conclusion}

Below mention tables are representing group wise impact of ancient yog

$1^{\text {st }}$ psycho-behavioral component of "Group-I" under Table 1 is related to "Depression". The concept of "Depression" in this study is "one kind of mood characterized by varying degrees of sadness, disappointment, loneliness, hopelessness, self-doubt, and guilt. These feelings can be quite intense and may persist long periods of time". Indeed, it is observed from above table that on the aspect "Depression" $97.50 \%$ (975) youths are feeling positive changes after practicing yog from the theological organization.

$2^{\text {nd }}$ psycho-behavioral component of Table 1 is "Frustration". The meaning of "Frustration" in this study is "One type of emotion that occurs in situations where a person is blocked from reaching the desired outcome". On the aspect "Frustration" $98.60 \%$ youths is assured that they are realized positive changes after practicing yog.

$3^{\text {rd }}$ psycho-behavioral component of Table 1 is "Grief", here in this study the word "Grief" interpreted as an "Intense sorrow". Significantly $98.40 \%$ scholars are assured that yog is able to generate positive changes on "Grief".

$4^{\text {th }}$ psycho-behavioral component of Table 1 is "Insecurity". Definition of "Insecurity" in this study is "lack of protection". It is noticed from above table that regarding the issue of "Insecurity" $98.60 \%$ people are assured that they realized positive outcome after practicing yog.

$5^{\text {th }}$ psycho-behavioral component of Table 1 is "Jealousy". Definition of "Jealousy" in this research is "Complex emotion that encompasses many or different kinds of feelings ranging from fear of abandonment to rage and humiliation". It is clear from above table that $98.50 \%$ people are recognized positive changes on "Jealousy" because of yog practice.

Table I Psycho-behavioral impact of yog based on 12 psycho-behavioral components under "Group-l"

\begin{tabular}{lll}
\hline $\begin{array}{l}\text { Psycho-behavioral } \\
\text { component }\end{array}$ & $\begin{array}{l}\text { Positive response } \\
\text { (score from } \mathbf{2}^{\text {nd }} \text { round- } \text { I }^{\text {st }} \text { round) }\end{array}$ \\
\hline 1 & Depression & $97.50 \%(975)$ \\
2 & Frustration & $98.60 \%(986)$ \\
3 & Grief & $98.40 \%(984)$ \\
4 & Insecurity & $98.60 \%(986)$ \\
5 & Jealousy & $98.50 \%(985)$ \\
6 & Mental irritation & $98.80 \%(988)$ \\
7 & Nervousness & $99.30 \%(993)$ \\
8 & Stress & $98.80 \%(988)$ \\
9 & Tension & $98.80 \%(988)$ \\
10 & Annoy & $98.70 \%(987)$ \\
11 & Quarrel intention & $99.10 \%(991)$ \\
12 & Malicious intention & $98.80 \%(988)$ \\
& Total & $98.66 \%(11839$ out of 39,000) \\
\hline
\end{tabular}

$6^{\text {th }}$ psycho-behavioral component of Table 1 is "Mental irritation". The meaning of "Mental irritation" in this study is "The state of feeling annoyed, impatient, or slightly angry". Yog is able to capture "Mental irritation" it is proved from above table and $98.80 \%$ people are assured it.

$7^{\text {th }}$ psycho-behavioral component of Table 1 is "Nervousness". In this study conception of "Nervousness" is used as "Having or showing feelings of being worried and afraid about what might happen". Significantly $99.30 \%$ people are assured that yog is able to address "Nervousness".

$8^{\text {th }}$ psycho-behavioral component of Table 1 is "Stress". Meaning of "Stress" in this study is "Feeling of strain and pressure". 98.80\% scholars are certified that they feel positive outcome after practicing yog.

$9^{\text {th }}$ psycho-behavioral component of Table 1 is "Tension". Definition of "Tension" in this research is "Emotion of physical and psychological strain joined by discomfort, unease, and pressure to look for alleviation via talking or acting" and from above table, it seemed that ancient yog able to annihilate "Tension", $98.80 \%$ people assured it.

$10^{\text {th }}$ psycho-behavioral component of Table 1 is "Annoy". The meaning of "Annoy" in this research is used as "Disturb or bother (a person) in a way that displeases, troubles, or slightly irritates". Significantly it is observed from above table that $y 0 g$ is able to provide the positive impact on the issue of "Annoy", $98.70 \%$ people have assured it.

$11^{\text {th }}$ psycho-behavioral component of Table 1 is "Quarrel intention". In this study, the concept "Quarrel intention" is defined as 
"Squabble approaches". Regarding the issue of "Quarrel intention" $99.10 \%$ people are assured positive effect after practicing yog.

$12^{\text {th }}$ psycho-behavioral component of Table 1 is "Malicious intention" and in this study, it is conveying the perception of "Feelings to hurt someone". Although on the aspect of "Malicious intention" 98.80\% people are realized positive outcome after practicing yog.

Below mention Table 2 is reflecting the impact of yog practices related to the 11 different psycho-behavioral components under the category of "Group-II":

Table 2 Psycho-behavioral impact of yog based on II psycho-behavioral components under "Group-II"

\begin{tabular}{lll}
\hline Psycho-behavioral component & $\begin{array}{l}\text { Positive response } \\
\text { (score from 2 } \mathbf{2}^{\text {nd }} \text { round- } \text { I }^{\text {st }} \text { round) }\end{array}$ \\
\hline I & Mental calmness & $98.80 \%(988)$ \\
2 & Altruism & $98.20 \%(982)$ \\
3 & Patience & $98.80 \%(988)$ \\
4 & Social accountability & $987(98.70 \%)$ \\
5 & Self-Confidence & $989(98.90 \%)$ \\
6 & Empathic outlook & $988(98.80 \%)$ \\
7 & Integrity & $988(98.80 \%)$ \\
8 & Non-judgmental attitude & $989(98.90 \%)$ \\
9 & Non-violence attitude & $991(99.10 \%)$ \\
10 & Punctuality & $989(98.90 \%)$ \\
II & Dignity & $988(98.80 \%)$ \\
& Total & $98.79 \%(10867$ Out of 39000) \\
\hline
\end{tabular}

$1^{\text {st }}$ psycho-behavioral component of Table 2 is "Mental calmness", the perception of "Mental calmness" in this study is "Peaceful mental or emotional state". Significantly $98.80 \%$ scholars are assured that the level of "Mental calmness" has been increased after practicing yog.

$2^{\text {nd }}$ psycho-behavioral component of Table 2 is "Altruism". The conception of "Altruism" in this study is "Feelings of humanity". Particularly $98.80 \%$ respondents are realized that the sensation of "Altruism" is increased in their life after practicing yog.

$3^{\text {rd }}$ psycho-behavioral component of Table 2 is "Patience" and the definition of "Patience" in this research is "Capacity to accept or tolerate delay, problems, or suffering without becoming annoyed or anxious". Merely $98.20 \%$ scholars are conveyed that level of "Patience" in their life is going upward after practicing yog.

$4^{\text {th }}$ psycho-behavioral component of Table 2 is "Social accountability". The description of "Social accountability" in this research is "Approach towards building accountability that relies on civic engagement, i.e., in which it is ordinary citizens and/or civil society organizations who participate directly or indirectly in exacting accountability". The feedback of $98.80 \%$ scholars is conscience of "Social accountability" is growing in their life after practicing yog.

$5^{\text {th }}$ psycho-behavioral component of Table 2 is "Self-Confidence" and it is used as "Confidence in one's own worth or abilities; selfrespect" in this study. Particularly $98.70 \%$ people are observed that the level of "Self-Confidence" is arising after practicing yog

$6^{\text {th }}$ psycho-behavioral component of Table 2 is "Empathic outlook" and in this research, it is carrying the sense of "Understand situation of a person from his/her perspective." Out of the total number of respondents $98.90 \%$ are shared that level of "Empathic outlook" is growing after practicing $y o g$.

$7^{\text {th }}$ psycho-behavioral component of Table 2 is "Integrity". Significantly the terminology of "Integrity" is used as "Quality of being honest and having strong moral principles in this study. Out of the total number of respondents $98.80 \%$ scholars are recognized that the level of "Integrity" in their life has been improved after practicing of yog.

$8^{\text {th }}$ psycho-behavioral component of Table 2 is "Non-judgmental attitude". The conception of "Non-judgmental attitude" in this study is "Stay away from judgmental approaches". Among the total $98.80 \%$ youths are realized the status of "Non-judgmental attitude" in their daily life is growing after practicing yog.

$9^{\text {th }}$ psycho-behavioral component of Table 2 is "Non-violence attitude". The conception of "Non-violence attitude" is used as "Peaceful and polite approaches or non-aggressive approaches" in this study. Particularly $99.10 \%$ yog scholars are observed that for the effect of $y o g$ practice the number of "Non-violence attitude" in their life is increasing day to day.

$10^{\text {th }}$ psycho-behavioral component of Table 2 is "Punctuality" and it is defined as "Able to complete a required task or fulfill an obligation before or at a previously designated time" in this study. Indeed, 98.90\% yog scholars are assured that for the effect of yog practice they are realized the trend of "Punctuality" in their life is going to upstairs.

$11^{\text {th }}$ psycho-behavioral component of Table 2 is "Dignity" and in this research, it is used to represent the sense "Inherent nobility or quality of being worthy of honor or respect". Particularly $98.80 \%$ scholars are shared that the level of "Dignity" in their life is increasing after practicing yog.

Below mention Table 3 is reflecting the impact of yog practices related to the 11 different psycho-behavioral components under the category of "Group-III":

$1^{\text {st }}$ psycho-behavioral component of Table 3 is "Acceptance" and in this research, it is representing the conception of "Action of consenting to receive or undertake something offered". Consciously $98.80 \%$ youths are shared that the level of "Acceptance" on their day to day life is increasing after practicing $y o g$.

$2^{\text {nd }}$ psycho-behavioral component of Table 3 is "Adjustment". The definition of "Adjustment" in this study is "Level of balance or tranquility joining people and their surroundings or climate". Total $98.90 \%$ scholars are assured that the level of "Adjustment" is growing for the effect of yog practice.

$3^{\text {rd }}$ psycho-behavioral component of Table 3 is "Attention" and the conception of "Attention" is "Capacity to maintain selective or sustained concentration" in this research. Particularly $98.80 \%$ youths are ensured that the intention of "Attention" towards the particular subject is growing for the effect of $y$ og.

$4^{\text {th }}$ psycho-behavioral component of Table 3 is "Concentration" and it is carrying the meaning of 
"Intense mental application; complete attention" in this study. Regarding the context $99.10 \%$ youths are recognized that the level of "Concentration" is going upstairs for the effect of yog practice.

Table 3 Psycho-behavioral impact of yog based on II psycho-behavioral components under "Group-III"

\begin{tabular}{lll}
\hline Psycho-behavioral component & $\begin{array}{l}\text { Positive response } \\
\text { (score from } 2^{\text {nd }} \text { round- } \text { I }^{\text {st }} \text { round) }\end{array}$ \\
\hline I & Acceptance & $98.80 \%(988)$ \\
2 & Adjustment & $98.90 \%(989)$ \\
3 & Attention & $98.80 \%(988)$ \\
4 & Concentration & $99.10 \%(991)$ \\
5 & Impartiality & $99.00 \%(990)$ \\
6 & Decision-making time & $98.90 \%(989)$ \\
7 & Emotional control & $99.00 \%(990)$ \\
8 & Eye-hand coordination & $96.10 \%(961)$ \\
9 & Recollection & $98.90 \%(989)$ \\
10 & Notice and situation analysis & $99.00 \%(990)$ \\
II & Reacting/ responding time & $98.80 \%(988)$ \\
& Total & $98.66 \%(10853$ out of 1000) \\
\hline
\end{tabular}

$5^{\text {th }}$ psycho-behavioral component of Table 3 is "Impartiality". The meaning of "Impartiality" in this research is "Unbiased or unprejudiced attention". The tendency of "Impartiality" is increasing after practicing yog and total $99.00 \%$ scholars are realized it.

$6^{\text {th }}$ psycho-behavioral component of Table 3 is "Decision-making time", in this study it is used to as "Time to take decision". It is clear from the above table that yog able to control decision-making power, $98.90 \%$ scholars shared that after practicing yog the duration of "Decision making time" is gradually going to short in their life.

$7^{\text {th }}$ psycho-behavioral component of Table 3 is "Emotional control". The conception of "Emotional control" in this study is "Power to manage sentimental reaction". The feedbacks of $99.00 \%$ scholars are yog is able to do "Emotional control" in their life.

$8^{\text {th }}$ psycho-behavioral component of Table 3 is "Eye-hand coordination". Here in this study the conception of "Eye-hand coordination" it is used as "Coordination between eye and hand during visible communication with other". Coordination and the right balance between eye and hand during physical communication are important issues to develop self-impression and motivating other. According to above table, $96.10 \%$ scholars are agreed that after practicing yog they are able to keep balance on "Eye-hand coordination" during face to face communication with other.

$9^{\text {th }}$ psycho-behavioral component of Table 3 is "Recollection". The concept of "Recollection" in this research is "Faculty of remembering something". Particularly $98.90 \%$ scholars are realized that their "Recollection" mechanism obtaining more strength after practicing yog. The remarkable point is people are able to strengthen their memory during yog practice.

$10^{\text {th }}$ psycho-behavioral component of Table 3 is "Notice and situation analysis". In this study, the conception of "Notice and situation analysis" is "Capability of observation and analyzing the situation". Regarding this issue $99.00 \%$ scholars are realized that the capacity and power of "Notice and situation analysis" is increasing after involved with yog practice.

$11^{\text {th }}$ psycho-behavioral component of Table 3 is "Reacting/ responding time". In this study, it is used as "Time duration of respond". Regarding the issue $98.80 \%$ scholars are observed that in the time of interaction with other the "Reacting/ responding time" is decreeing gradually after practicing yog.

Below mention Table 4 is reflecting the impact of yog practices related to the 5 different psycho-behavioral components under the category of "Group-IV":

Table 4 Psycho-behavioral impact of yog based on 5 psycho-behavioral components under "Group-IV"

\begin{tabular}{|c|c|c|}
\hline \multicolumn{2}{|c|}{ Psycho-behavioral component } & \multirow{2}{*}{$\begin{array}{l}\text { Positive response } \\
\text { (score from } 2^{\text {nd }} \text { round- I }{ }^{\text {st }} \text { round) } \\
98.80 \%(988)\end{array}$} \\
\hline 1 & $\begin{array}{l}\text { Avoiding unwanted } \\
\text { circumstance }\end{array}$ & \\
\hline 2 & Manner & $98.90 \%(989)$ \\
\hline 3 & Politeness & $98.80 \%(988)$ \\
\hline 4 & Solidarity & $98.70 \%(987)$ \\
\hline \multirow[t]{2}{*}{5} & Cheerful view & $98.80 \%(988)$ \\
\hline & Total & $98.80 \%$ (4940 out of 39000$)$ \\
\hline
\end{tabular}

Among 5 different psycho-behavioral components $1^{\text {st }}$ psychobehavioral component of Table 4 is "Avoiding unwanted circumstance". Here in this study the meaning of "Keep distance from unfair situation". It is observed from the feedback of $98.80 \%$ respondents that intention of "Avoiding unwanted circumstance" is escalating day to day in their life after practicing yog.

$2^{\text {nd }}$ psycho-behavioral component of Table 4 is "Manner". In this study, it is defined as "Code of behaviour that delineates expectations for social behaviour according to contemporary conventional norms within a society, social class, or group". On this aspect, $98.90 \%$ scholars are assured that the "Manner" of a person is making stronger after practicing yog. Therefore, it is clear that yog is competent to develop "Manner".

$3^{\text {rd }}$ psycho-behavioral component of Table 4 is "Politeness". The meaning of "Politeness" in this study is "Showing good behaviour (etiquette) toward others". On daily life the sensitivity of "Politeness" of a person is growing day to day - this is the realization of $98.80 \%$ scholars.

$4^{\text {th }}$ psycho-behavioral component of Table 4 is "Solidarity". In this research, it is defined as "Unity (as of a group or class) which produces or is based on unities of interests, objectives, standards, and sympathies. It refers to the ties in a society that bind people together as one)". Regarding this aspect the feedback of $98.70 \%$ scholars are yog is able to build-up the sensation of "Solidarity" on personality.

$5^{\text {th }}$ psycho-behavioral component of Table 4 is "Cheerful view", in this study it is interpreted as "Optimistic appearance". Principally $98.80 \%$ scholars are realized that the level of "Cheerful view" is growing day to day on their personality after practicing yog.

It is clear from above intervention that yog is able to carry positive changes on 39 psycho-behavioral components i.e- 

1. Depression
2. Frustration
3. Grief
4. Insecurity
5. Jealousy
6. Mental irritation
7. Nervousness
8. Stress
9. Tension Annoy
10. Quarrel intention
11. Malicious intention
12. Mental calmness
13. Altruism
14. Patience
15. Social accountability
16. Self-Confidence
17. Empathic outlook
18. Integrity
19. Non-judgmental attitude
20. Non-violence attitude
21. Punctuality
22. Dignity
23. Acceptance
24. Adjustment
25. Attention
26. Concentration
27. Impartiality
28. Decision making time
29. Emotional control
30. Eye-hand coordination
31. Recollection
32. Notice and situation analysis
33. Reacting/ responding time
34. Avoiding unwanted circumstance
35. Manner
36. Politeness
37. Solidarity

Cheerful view related to the daily life of present generation youth of KMA region. So, as a conclusion it would like to demand that yog is also one kind of BCC (Behaviour Change Communication).

Moreover, it is observed during data analysis multi-practice is more effective than single practice.

\section{Acknowledgments}

None.

\section{Conflict of interest}

Authors declare there is no conflict of interest in publishing the article.

\section{References}

1. Bicard SC, Bicard DF. Defining behavior. The IRIS Center. 2012. 